\title{
Correction to: Predicting global numbers of teleomorphic ascomycetes
}

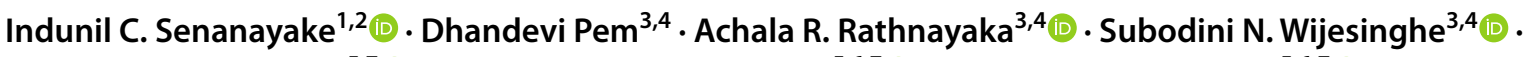 \\ Saowaluck Tibpromma ${ }^{5,7}$ (1) Dhanushka N. Wanasinghe ${ }^{5,6,7}$ (D) Rungtiwa Phookamsak, ${ }^{5,6,7}$ (i) . \\ Nuwan D. Kularathnage ${ }^{2,3,4}(\mathbb{D}) \cdot$ Deecksha Gomdola ${ }^{3,4}(\mathbb{C}) \cdot$ Dulanjalee Harishchandra $^{3,4,8}(\mathbb{D}) \cdot$ \\ Lakmali S. Dissanayake ${ }^{9}$. Mei-mei Xiang ${ }^{2}$. Anusha H. Ekanayaka ${ }^{3,4,5}$. Eric H. C. McKenzie ${ }^{10}$ (1) \\ Kevin D. Hyde ${ }^{2,3,4,5} \cdot$ Hao-xing Zhang ${ }^{1} \cdot$ Ning Xie $^{1}$
}

Published online: 1 March 2022

(c) The Author(s) 2022

\section{Correction to: Fungal Diversity https://doi.org/10.1007/s13225-022-00498-w}

In the section Biodiversity hotspots, the origin of most ascomycetous type collections was incorrectly worded. The original article has been corrected.

Open Access This article is licensed under a Creative Commons Attribution 4.0 International License, which permits use, sharing, adaptation, distribution and reproduction in any medium or format, as long as you give appropriate credit to the original author(s) and the source, provide a link to the Creative Commons licence, and indicate if changes were made. The images or other third party material in this article are included in the article's Creative Commons licence, unless indicated otherwise in a credit line to the material. If material is not included in the article's Creative Commons licence and your intended use is not permitted by statutory regulation or exceeds the permitted use, you will need to obtain permission directly from the copyright holder. To view a copy of this licence, visit http://creativecommons. org/licenses/by/4.0/.
The original article can be found online at https://doi.org/10.1007/ s13225-022-00498-w.

\section{Ning Xie}

Shainin@msn.cn

1 Guangdong Provincial Key Laboratory for Plant Epigenetics, College of Life Science and Oceanography, Shenzhen University, Nanhai Avenue, Nanshan, Shenzhen 3688, Guangdong, China

2 Innovative Institute for Plant Health, Zhongkai University of Agriculture and Engineering, Haizhu District, Guangzhou 510225, China

3 Center of Excellence in Fungal Research, Mae Fah Luang University, Chiang Rai 57100, Thailand

4 School of Science, Mae Fah Luang University, Chiang Rai 57100, Thailand

5 Honghe Center for Mountain Futures, Kunming Institute of Botany, Chinese Academy of Sciences, Honghe County 654400, Yunnan, China
Centre for Mountain Futures (CMF), Kunming Institute of Botany, Kunming 650201, Yunnan, China

7 CIFOR-ICRAF China Program, World Agroforestry (ICRAF), Kunming 650201, Yunnan, China

8 Beijing Key Laboratory of Environment Friendly Management On Fruit Diseases and Pests in North China, Institute of Plant and Environment Protection, Beijing Academy of Agriculture and Forestry Sciences, Beijing 100097, China

9 Engineering Research Center of the Utilization for Characteristic Bio-Pharmaceutical Resources in Southwest, Ministry of Education, Guizhou University, Guiyang 550025, Guizhou, China

10 Manaaki Whenua-Landcare Research, Auckland Mail Centre, Private Bag 92170, Auckland 1142, New Zealand 